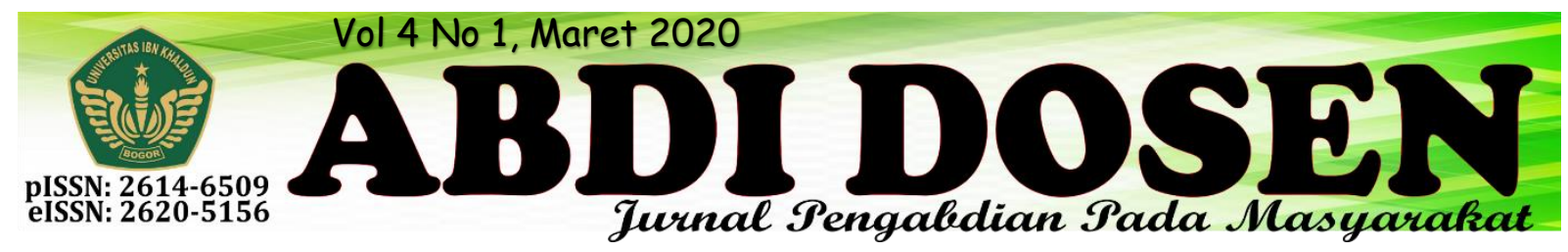

\title{
PEMBERDAYAN MAJLIS TA'LIM AINAL YAKIN DALAM MEMBANGUN KETAHANAN EKONOMI KELUARGA MELALUI USAHA TAMBAHAN DI DESA LEUWILIANG
}

\author{
Imas Kania Rahman ${ }^{1}$, Yudiana ${ }^{2}$, Revi Saputra ${ }^{3}$ \\ imas.kania@uika-bogor.ac.id ${ }^{1}$ \\ yudiana@uika-bogor.ac.id ${ }^{2}$ \\ Dosen Fakultas Agama Islam, Dosen Fakultas Ekonomi dan Bisnis², Mahasiswa KKN Kelompok 01\&02 Tahun
} $2019^{3}$

\begin{abstract}
ABSTRAK
KKN Tematik Terintegrasi bagi masyarakat yakni untuk meningkatkan kesadaran masyarakat dengan berperan aktif dalam mengembangkan produktifitas sumber daya pembangunan sesuai dengan fasilitas yang dimiliki. Kegiatan KKN Tematik Terintegrasi UIKA Bogor Tahun 2019 merupakan salah satu kegiatan dengan pendekatan community development, dimana pada pelaksanaan kegiatan ini melakukan proses perencanaan sekaligus aksi program pendampingan masyarakat baik pada aspek sosial, ekonomi, kesehatan, pendidikan, hukum, dan agama maupun teknologi tepat guna secara terpadu. KKN yang diselenggarakan tahun 2019 oleh kelompok 1 dan 2 terfokus di Desa Leuwiliang yaitu sebuah desa yang sedang mengarah ke desa perkotaan dengan luas wilayah $\pm 297,00$ Hektar, terletak di Kecamatan Leuwiliang, Kabupaten Bogor yang berbatasan langsung dengan Kecamatan Cibungbulang dan Kecamatan Leuwisadeng. Kegiatan yang dilakukan oleh kelompok 1 dan 2 terbagi menjadi tiga program. Program unggulan yaitu pelatihan merajut, pelatihan membuat es krim cincau, pelatihan membuat susu jahe merah, pelatihan membuat bunga dari pelepah bambu, pelatihan membuat pot bunga dari botol bekas, dan pelatihan membuat kotak tisu. Program pendukung diantaranya yaitu mengajar Bahasa Inggris, Pengenalan dasar komputer dan penggunaan Microsoft office, sosialisasi dan penyuluhan kesehatan (Hipertensi), Program sosialisasi pembukuan, sosialisasi pemasaran produk berbasis IT, sosialisasi KUR (Kredit Usaha Rakyat), penanaman 500 bibit pohon, dan penyuluhan dan sosialisasi pemanfaat kotoran ternak dan sampah organik menjadi biogas. Program partisipasi yaitu kerja bakti pengajian anak-anak, ibu-ibu, dan bapak-bapak warga kampung Batas, hari raya Idul Adha, dan memeriahkan hari kemerdekaan Republik Indonesia ke 74.
\end{abstract}

\section{Kata Kunci : KKN, Desa Leuwiliang, Program KKN.}

\section{PENDAHULUAN}

\section{Analisis Situasi}

Desa Leuwiliang adalah sebuah desa

yang sedang mengarah ke desa perkotaan dengan luas wilayah $\pm 297,00$ Hektar, terletak di kecamatan Leuwiliang,
Kabupaten Bogor yang berbatasan langsung dengan Kecamatan Cibungbulang dan Kecamatan Leuwisadeng yang secara geografis luas dan batas wilayah Desa Leuwiliang sebagai berikut: 


\begin{tabular}{|c|l|l|l|}
\hline No & Batas & Desa/Kelurahan & \multicolumn{1}{|c|}{ Kecamatan/Kabupaten } \\
\hline 1 & Utara & Desa Karehkel & Kecamatan Rumpin \\
\hline 2 & Selatan & Desa Leuwimekar & Kabupaten Sukabumi \\
\hline 3 & Timur & Desa Cibeber 1 & Kecamatan Sadeng \\
\hline 4 & Barat & Desa Galuga & Kecamatan Cibungbulang \\
\hline
\end{tabular}

Dari data profil desa dan kelurahan yang diperoleh, tingkat kepadatan penduduk rata-rata untuk Desa 5.676,43 jiwa/km. Secara umum dapat dijelaskan bahwa penduduk Desa Leuwiliang bermata pencaharian wiraswasta, pedagang keliling, buruh harian lepas, petani, dan selebihnya memiliki mata pencaharian yang bervariasi.

Dilihat dari segi pendidikan yang cukup rendah, menjadikan timbulnya beberapa masalah di masyarakat dengan beberapa bidang diantaranya, ekonomi, kesehatan, dan pendidikan. Hal itu dikarenakan kurangnya ilmu pengetahuan.

\section{Permasalahan yang dihadapi}

Terdapat beberapa permasalahan yang ada di Desa Leuwiliang, diantaranya :

1. Kurangnya perhatian orang tua terhadap pendidikan anaknya

2. Beberapa masyarakat yang meminjam uang melalui bank keliling

\section{Solusi yang di Tawarkan}

Setelah memahami beberapa permasalahan yang terjadi di Desa Leuwiliang, maka kami menawarkan beberapa solusi untuk membantu memajukan Desa Leuwiliang, diantaranya :
1. Adanya program les bahasa Inggris dan bahasa Arab untuk memberikan pengetahuan tambahan kepada anakanak.

2. Adanya program mengajar bahasa Inggris dan Pendidikan Agama Islam di SDN Gunung Sodong 01 dan memberikan pengetahuan tambahan kepada anak-anak.

3. Adanya program penyuluhan hipertensi dan pemeriksaan hipertensi kepada warga.

4. Adanya program pelaksanaan HUT RI ke 74 di Kp. Batas RT 03 RW 08 Desa Leuwiliang.

5. Adanya pelatihan membuat suatu produk yang menarik untuk dijual, sehingga menambah pendapatan dan membangun ketahanan ekonomi keluarga.

6. Adanya sosialisasi pembukuan agar warga dapat mengelola keuangannya dengan baik dan benar.

7. Ikut partisipasi dalam acara hari raya Idul Adha di Kp. Batas RT 03 RW 08 Desa Leuwiliang. 


\section{METODE PENGABDIAN}

Tahapan pelaksanaan untuk kegiatan ini sebagaimana terlihat pada bagan:

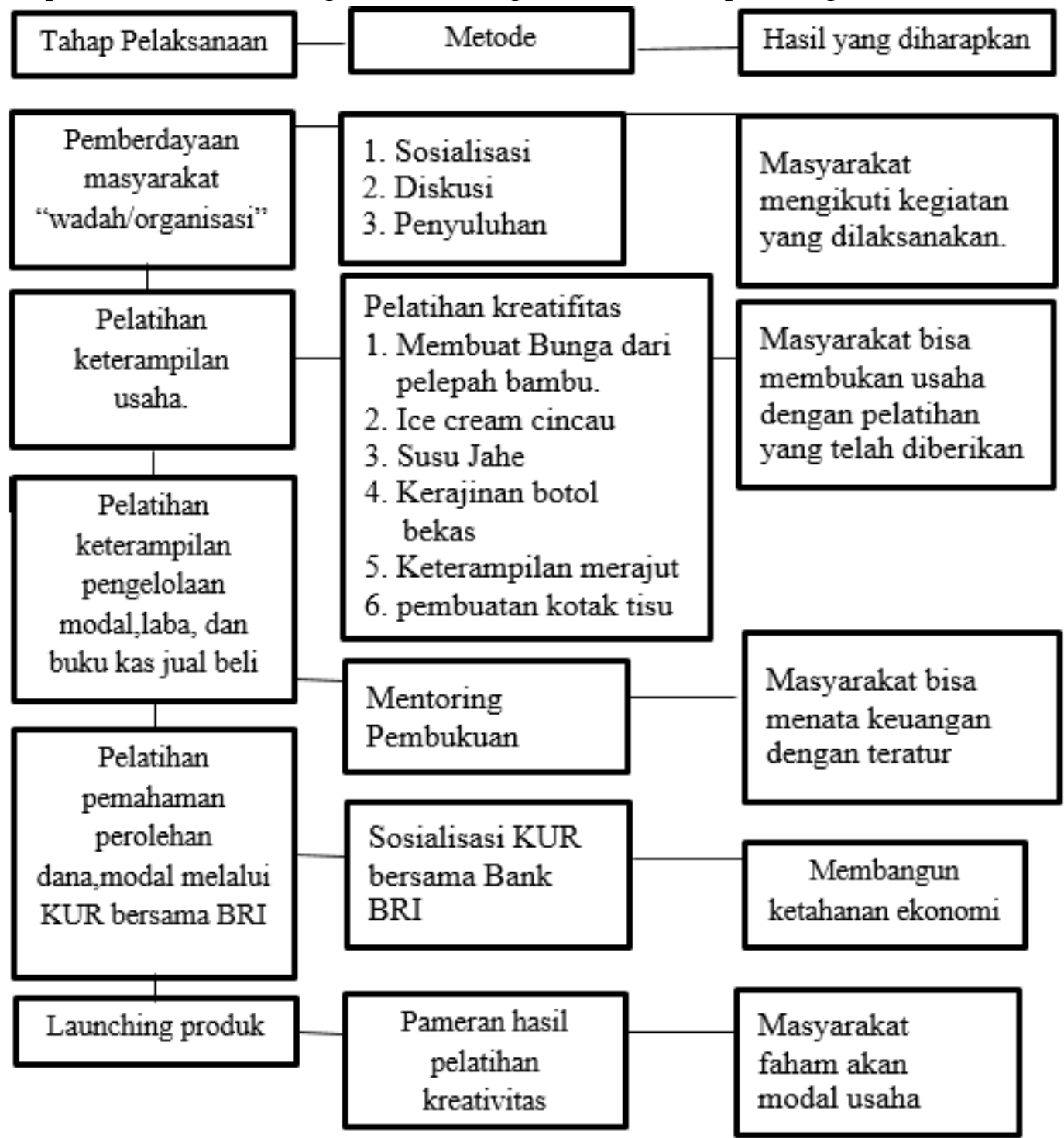

\section{Metode Pendekatan}

Pendekatan dapat dikatakan sebagai sudut pandang seseorang dalam memandang suatu hal (Dici,2016). Pendekatan yang digunakan dalam kegiatan ini adalah :

1. Pendekatan religius, yaitu pendekatan yang menggunakan nilai-nilai agama sebagai basis kegiatan. Pendekatan ini dipengaruhi oleh faktor keimanan, pengalaman keagamaan, rasa tanggung jawab dan pengetahuan.

2. Pendekatan organisasi, yaitu pendekatan dimana seluruh kegiatan diorganisir oleh Majlis Ta'lim Ainal Yakin.

3. Pendekatan kekerabatan, artinya bahwa pembinaan yang dilakukan senantiasa dikaitkan dalam rangka membangun kekerabatan antar masyarakat. Nurhayati (2005) menemukan bahwa faktor pendukung toleransi umat Islam dengan Hindu adalah adanya sistem kekerabatan.

4. Pendekatan berdasarkan karakter masyarakat, yakni pembinaan yang dilakukan akan disesuaikan dengan karakter masyarakat. Joyce dan Weil 
(1996) mengungkapkan bahwa model pendidikan yang relevan dengan perilaku sosial dan nilai adalah dengan banyak memberikan permainan peran. Hal ini dilakukan untuk memberi pengalaman riil kepada peserta didik tentang sesuatu yang dilakukan atau dirasakan oleh orang lain. Memang, dalam prakteknya, tidak seluruh aspek harus menggunakan permainan ini. Dalam beberapa hal, terdapat kegiatan-kegiatan yang hanya golongan tertentu untuk melakukannya. Sejalan dengan konsep Joyce dan Weil, cooperative learning yang digagas Slavin (2005) dapat digunakan untuk membangun kesadaran toleransi masyarakat. Hal ini karena penekanan dari konsep pendidikan ini adalah kerjasama yang merupakan urat nadi toleransi. Dengan demikian, model pendidikan yang akan dibangun menggunakan dua konsep utama yaitu role playing model dan cooperative learning model.

5. Pendekatan berbasis IT (Ilmu Teknologi), artinya melalui pemanfaatan ilmu teknologi yaitu dengan cara memberikan arahan untuk menjangkau jaringan yang luas,

\section{HASIL DAN PEMBAHASAN}

Pelaksanaan KKN UIKA 2019 dimulai pada tanggal 6 Agustus sampai dengan 6 September 2019 yang pelaksanaannya dilakukan oleh kelompok KKN 1 dan 2 serta masyarakat Kampung Batas yang berada di RT 03 RW 08 . Adapun program KKN dirinci sebagai berikut :

\section{A. Program Unggulan}

1. Pelatihan Merajut

2. Pelatihan Membuat Es Krim Cincau masyarakat mampu mengikuti perkembangan di era globalisasi ini.

\section{Langkah Evaluasi}

Menurut Mahirah (2017) dia mengatakan bahwa evaluasi memiliki dua makna, pertama adalah sistem evaluasi yang memberikan informasi yang optimal. Kedua adalah manfaat yang dicapai dari evaluasi. Evaluasi yang akan dilakukan terdiri dari :

1. Evaluasi proses, yang terkait dengan perencanaan, pelaksanaan dan monitoring kegiatan. Evaluasi proses akan dilakukan setiap pekan bersama dengan koordinator masing-masing kreativitas.

2. Evaluasi hasil, yang akan dilaksanakan setelah kegiatan pelatihan kreativitas dilaksanakan. Evaluasi hasil ditujukan untuk menguji pemahaman masyarakat dengan target capaian $100 \%$. Selain itu, evaluasi hasil akan menjembatani pada peningkatan pendapatan masyarakat.

3. Evaluasi dampak, yang akan dilakukan 1 (satu) bulan setelah pelaksanaan pembinaan. Evaluasi dampak diarahkan untuk melihat efektivitas model pembinaan dan keberlangsungan industri rumah tangga (Gall, Gall, dan Borg, 2003).

3. Pelatihan Membuat Susu Jahe Merah

4. Pelatihan Membuat Bunga dari Pelepah Bambu

5. Pelatihan Membuat Pot Bunga dari Botol Bekas

6. Pelatihan Membuat Kotak Tisue

B. Program Pendukung

1. Mengajar Bahasa Inggris

2. Mengajar Pendidikan Agama Islam

3. Pengenalan dasar komputer dan penggunaan Microsoft office 
4. Senam bersama masyarakat Kampung Batas RT 03 RW 08

5. Sosialisasi menabung di SDN Gunung Sodong 01

6. Sosialisasi dan penyuluhan kesehatan (Hipertensi)

7. Program sosialisasi pembukuan

8. Sosialisasi pemasaran produk berbasis IT

9. Seminar edukasi pasar modal syariah

10. Penyuluhan permasalahan hukum di Kecamatan Leuwiliang

11. Sosialisasi KUR (Kredit Usaha Rakyat)

\section{KESIMPULAN}

Kegiatan KKN yang dilakukan di Desa Leuwiliang dengan sasaran masyarakat kampung Batas, Kecamatan Leuwiliang kabupaten Bogor, Sebagian dari masyarakat di kampung Batas banyak yang antusias terhadap kegiatan-kegiatan yang sudah disusun oleh kelompok KKN dan dengan antusias masyarakat yang sangat luar biasa sehingga program yang telah disusun bisa berjalan dengan lancar walau terkadang memiliki beberapa kendala akan tetapi program yang sudah tersusun bisa terlaksana berkat antusias masyarakat, adapun kesimpulan dari pelaksanaan program kerja $\mathrm{KKN}$ dimasyarakat yaitu :

1. Program kerja yang sudah disusun bisa berjalan dengan baik dan tanpa kendala walau ada beberapa perubahan jadwal pelaksanaan program kerja dan ada beberapa tambahan serta waktu pelaksanaan yang sesuai dengan apa yang sudah di tentukan dalam program kerja yang sudah disusun.

2. Semua program kerja yang telah disusun dan direncanakan dapat berjalan dengan lancar tanpa hambatan berkat antusias masyarakat kampung
12. Penanaman 500 bibit pohon

13. Penyuluhan dan sosialisasi pemanfaat kotoran ternak dan sampah organik menjadi biogas

14. Festival Anak Soleh

C. Program Partisipasi

1. Kerja bakti

2. Pengajian anak-anak, ibu-ibu, dan bapak-bapak warga kampung Batas

3. Hari raya Idul Adha

4. Memeriahkan hari kemerdekaan Republik Indonesia ke 74

Batas,Desa Leuwiliang dan kerja sama antara kelompok Mahasiswa KKN dengan ketua RT,RW dan para tokoh masyarakat yang ada dikampung Batas sehingga program kerja bisa terlaksana dengan baik.

\section{Dampak Bagi Masyarakat}

Dalam program yang dilaksanakan, dampak yang diperoleh masyarakat antara lain :

1. Dengan adanya bimbingan belajar, anak-anak yang berada di Kp. Batas termotivasi untuk mendapatkan ilmu tambahan dan anak-anak dapat meningkatkan kemampuannya dalam memahami pelajaran.

2. Pengajian anak-anak, manfaat yang diperoleh yaitu anak-anak mengetahui cara membaca Al-Qur'an yang benar dan mengetahui hokum tajwidnya.

3. Pengajian ibu-ibu dan bapak-bapak di Kp. Batas, manfaat yang diperoleh yaitu dapat mempererat tali silaturahmi antara masayarakat dengan mahasiswa.

4. Senam sehat, dengan adanya kegiatan ini dapat menambah kebugaran warga Kp. Batas dan mempererat tali silaturahmi. 
5. Penyuluhan dan cek hipertensi, manfaat yang di dapat oleh masyarakat yaitu mengetahui tekanan darah apakah tekanan darah sedang rendah, normal, atau tinggi.

6. Dengan adanya pelatihan dari berbagai macam kreativitas, masyarakat dapat melahirkan suatu karya baru yang nantinya dapat dijual untuk mempertahankan perekonomiannya dengan daya kreativitas yang tinggi dan hasil yang menarik. Mampu menjadikan suatu kreativitas sebagai langkah awal untuk berinovasi dan dapat meningkatkan kesejahteraan.

7. Program penyuluhan pembukuan, masyarakat dibimbing untuk bisa menyusun keuangan agar tertata dengan rapi, mengetahui harga penjualan suatu produk dan memperhitungkan keuntungan yang di dapat.

\section{REFERENSI}

Anditia, Dici Rizka. (2016) "Pendidikan Religius Yang Digunakan Siswa MI dalam Menjelaskan Fenomena Alam". Jurnal Cakrawala Pendas Vol. 2 No. 2 Edisi Juli 2016.

B, Mahirah. (2017) "Evaluasi Belajar Peserta Didik (Siswa)" JURNAL IDAARAH, VOL. I, NO. 2, DESEMBER 2017

Perdana, Amelia., Halilullah, Nurmalisa, Yunisca., (2013) "Pengaruh Pelaksanaan Kuliah Kerja Nyata (KKN) Terhadap Keterampilan Sosial M-ahasiswa Program Studi PPKN Universitas Lampung Tahun 2013”. Universitas Lampung.
8. Sosialisasi pemasaran produk berbasis IT, masyarakat dapat mengetahui bagaimana cara mengiklankan produknya melalui media online, sehingga mampu bersaing dan tidak tertinggal.

9. Sosialisasi KUR, masyarakat dapat mengetahui salah satu cara mendapatkan modal usaha melalui KUR (Kredit Usaha Rakyat)

10. Penanaman 500 bibit pohon dan kerja bakti, manfaat bagi masyarakat yaitu lingkungan menjadi bersih dan lahan tidak gersang.

11. Pemanfaatan kotoran ternak dan sampah organik menjadi biogas, manfaat yang dirasakan oleh masyarakat adalah menambah ilmu pengetahuan bahwa kotoran ternak dan sampah organik dapat diproses menjadi biogas.

Rahman, Imas Kania., Suherman., Zalfatun, Nisah., (2017) "Pemberdayaan Masyarakat, Karang Taruna dan Darma Wanita Dalam M-engentaskan Masalah Sampah dan Limbah di Desa Parung" Jurnal Volume 02 Nomor 02, Juni 2018.

Rini, Yuli Sectio., "Pendidikan : Hakekat, Tujuan, dan Proses" Jurnal Universitas Negeri Yogyakarta.

Fathimah Anissatul., Agnesia Utari, S Abdul Ridho.,

"Pemberdayaan Masyarakat Melalui Peningkatan Mutu Pendidikan, Ekonomi, dan Kesehatan Studi Kasus Desa Cibeber II" Jurnal Volume 03 Nomor 01, Maret 2019 